\title{
GENDERED VULNERABILITIES AND HEALTH INEQUITIES
}

\author{
Vanitha Kommu, Divya Alexander and Lakshmi Lingam
}

\section{Introduction}

Climate change has a profound and increasing impact on human health and well-being, as outlined in the earlier chapters of this book. Given the existing gender-based inequalities, climate change affects the lives of men, women and girls differently (WHO, undated). Understanding the multidimensional aspects of climate change specifically on women and their health is important in order for healthcare workers to build their sensitivity, and to respond pro-actively to ensure health and gender equity. It is useful to understand what causes these differential impacts, which are often referred to as being "gendered."

Gender is defined as the "socially constructed roles, behaviours, activities and attributes that a given society considers appropriate for men and women" (WHO Gender Fact Sheet) and people of other genders. However, gender construction not only leads to differential access to resources (land, property, income, education) but also leads to women and girls being marginalised and having lower access to public and private decision making and autonomy. This structural and systemic gender hierarchy in conjunction with other social stratifiers, such as class, caste, ethnicity, age, ability and citizenship status, produces differential exposure, differential response and differential outcomes to any given situation. Gender differentials in health linked to climate change, therefore, are a combined function of physiological, behavioural and socially constructed differences. The concerns discussed in this chapter cover key aspects linked to the United Nations Sustainable Development Goals that relate to health (Goal 3), gender equality (Goal 5) and climate action (Goal 13). This chapter will:

1. Outline the linkages between climate and gender-specific health impacts and examine the gender-based vulnerabilities that result in differentiated impacts.

2. Explore a gender-sensitive approach in existing healthcare systems, highlighting gaps and providing recommendations. 


\section{Climate change and gender-specific health impacts}

The key impacts of climate change are extreme weather events, altered air quality, favourable weather conditions for degradation and the spread of disease, and contamination of natural resources. Climate change is said to aggravate health risks in humans with gendered differentials, making women and children the most vulnerable (WHO, 2011). In the sections below, we closely study the gender-based vulnerabilities and undesirable impacts of climate-triggered events/alterations on women.

Vulnerability to extreme weather events: Globally, deaths related to natural disasters are higher among women, as they are generally not equipped with the necessary skills (e.g. swimming, running and climbing trees to protect themselves during floods), and also have poor access to climate-related information. Similarly, sociocultural norms, dress codes and women's responsibility for the elderly, children, people with disabilities and homestead livestock restrict women's mobility in general, and at the time of crises in particular (Box 9.1). These disasters may also disturb local security and safety systems, resulting in stress, conflicts and mental health-related issues among children and women (Bartlett, 2008).

Vulnerabilities to temperature variations: The physiological dispensation of women to increasing temperatures is different when compared to men, making them biologically vulnerable. Their heat dissipation through

\section{Box 9.1 Case study \\ The gendered impacts of the tsunami in South-East Asia, 2004}

The 2004 tsunami that decimated South East Asia killed 220,000 people and left 1.6 million homeless. A survey conducted by Oxfam revealed that four times as many women than men were killed in the tsunami-affected areas of Indonesia, Sri Lanka and India (MacDonald, 2005). The reasons were similar across countries: women couldn't swim or climb trees to escape, they stayed behind to look for their children or other relatives, they were at home while the men were out (away from the seafront), they were waiting on shore for the men to bring back the catch, or they were bathing in the sea at the time when the tsunami struck. There are both short-term and long-term consequences, resulting in an imbalance in the male-female survival ratio. Surviving women are far outnumbered by men in crowded relief and resettlement camps, putting them at increased risk for gender-based violence. The shortage of women can also lead to long-term risks including compromised education and reproductive health for women, as they start to get married younger and younger (Oxfam Briefing Note, 2005). 
sweat is less, metabolic rate is high and the subcutaneous fat is thick, which decreases radiative cooling (Duncan, 2006). High ambient temperatures can also lead to complications in pregnancy such as gestational hypertension, preeclampsia (Makhseed et al., 1999) and poor neonatal outcomes (Kakkad et al., 2014).

Vulnerabilities to air pollution: Air pollution contributes to climate change and is also exacerbated by it. According to some experimental studies, women demonstrate a higher burden due to pulmonary deposition of inhaled particles (Chen et al., 2005). Women are reportedly more susceptible to cardiovascular complications according to a study where the intimamedia thickness of arteries in women was significantly correlated with ambient levels of $\mathrm{PM}_{2.5}$, whereas in men it was not (Kunzli et al., 2005). Women have higher rates of anaemia in general, and particularly in India, which makes them more sensitive to airborne pollution than males (Sorensen et al., 2003). Further, women are more exposed to indoor air pollution (especially the particulate matter from fuelwood stoves), resulting in respiratory problems, cardiovascular risks, cataracts and adverse impacts on their reproductive health.

Vulnerabilities to water contamination: Both droughts and floods could result in water contamination. Inorganic contamination due to arsenic and fluoride concentrations seem to have a greater effect on women: women can experience negative pregnancy outcomes, skin hardening, spots and lesions and swelling of limbs due to high arsenic levels, and dental and skeletal deformities due to fluoride levels. Organic contamination also shows detrimental effects, especially in drought-prone regions where women have to rely on unsafe or contaminated sources. This leads to water-borne diseases such as diarrhoea. Hygienic practices are also compromised, resulting in "water-washed diseases" such as trachoma and scabies (WaterAid, 2002).

Vulnerability to food insecurity: Women are the worst affected by disruptions in food production as they are responsible for cooking, feeding, caring and nurturing family members, and collecting fodder for cattle. During times of food insecurity, women resort to extreme steps such as eating less, resorting to poor quality food and quitting meals. This contributes to malnutrition and increases their susceptibility to diseases. In some cultures, the household food hierarchies aggravate this further. Women have special nutritional needs, especially when they are pregnant and breastfeeding, which is unmet in most cases (especially in rural areas and among the urban poor) resulting in health issues. These deficiencies also undermine women's capacity to cope with the impacts of natural disasters (Cannon, 2002). The impact of climate change on food production often results in the migration of men, leaving women to shoulder the burden of agricultural work, cattle rearing, domestic work, care of the elderly and care of young children. Even if women do migrate, the stress related to finding work and the lack of basic facilities such as healthcare and sanitation, etc., affects 
them severely. Periods of food scarcity often also lead to marital stress, spousal violence, sexual abuse and other human rights violations.

Vulnerability to water scarcity: During dry seasons, especially in waterstressed areas, most of a woman's time and energy is spent on collecting water (Box 9.2). The laborious tasks of fetching and carrying water may cause damage to the neck and spine, leading to chronic skeletal pain in the long run.

Travelling long distances for water also increases exhaustion, exposure to heat stress and heat strokes, and threatens their safety by exposing them to violent crimes (Shiva \& Jalees, 2005). The quantity of water collected often does not meet the basic household requirements. The lack of sufficient clean water poses serious health risks to women, especially during menstruation and pregnancy, when the utmost care is required in terms of hygiene (Birch et al., 2012). The availability of freshwater is compromised in coastal areas due to saline water intrusion. This is further aggravated by the rise in sea levels, triggered by climate change.

\section{Box 9.2 Case study}

\section{The gendered impact of water scarcity due to climate change}

Seawater is the major polluter of groundwater in the coastal area of Odisha, according to a 2014 report by of the Ministry of Water Resources, Government of India. Kuntala Rout, 58, spends three, sometimes four, hours to fill enough water for everyone in the family, walking to the only hand pump $500 \mathrm{~m}$ outside her village, Kaliapat, a coastal village in Bhadrak district of Odisha. A single trip can take as much as 20 minutes to an hour, depending on the crowd around the hand pump. The groundwater in this area is five times as saline as fresh drinking water, because of an increase in sea levels, reduction in rainfall and excess drawing of groundwater. When the hand pump outside Kaliapat breaks down every few months, the women have to walk for over an hour to the neighbouring village to fill water. "Our bodies hurt, and we have joint and back pains," said Rout. "To reduce the consumption of water, we try not to drink much water." She is among dozens of women raising their voices through governmentrecognised Self-Help Groups (SHGs), which have formed federations in 11 gram panchayats across Bhadrak, with help from the NGO WaterAid India. Shortage of water, the need for more hand pumps and issues of sanitation in the aftermath of a natural disaster, are issues that women raise, in which the men are not interested.

Source: Shetty, 2019. 
Vulnerabilities of pregnant women: Pregnant women are vulnerable to extreme temperatures that could cause dehydration, releasing labourinducing hormones. Newborns are also sensitive to temperature extremes because of their limited capacity for temperature regulation. Both mothers and infants are more likely to be exposed to indoor air pollution from traditional cookstoves. Exposure to indoor air pollution during pregnancy results in respiratory infections and low birth weight or premature births in newborns. The inhalation of particulate matter results in an increased risk of adverse reproductive, cardiovascular and respiratory outcomes. According to a study on saline water contamination of drinking water in Bangladesh, large numbers of pregnant women in coastal areas are being diagnosed with pre-eclampsia, eclampsia and hypertension (Khan et al., 2014).

\section{A gender-sensitive approach in health services}

Despite the existing knowledge and understanding of the health impacts of climate variations, gendered vulnerabilities and differentiated impacts, current health systems are not sufficiently geared towards incorporating a much-needed gender-sensitive approach. Also lacking is a policy environment conducive to the implementation of gender-sensitive programmes that focus on capacity enhancement, and creating/strengthening facilities.

Public health surveillance needs to track the gender-disaggregated data of human exposure to climatic events or changes in the environment, assess the impact in a gender-sensitive manner, and monitor individuals and communities utilising Human Bio Monitoring (HBM) investigations. Health professionals play a key role in promoting a gender-sensitive understanding of the links between climate change and health, along with mitigation actions and responses. To do this, the first step is for health professionals themselves to be educated on the issue. The case study in the box shows that such sensitisation is an immediate requirement within the healthcare sector (Box 9.3).

\section{Box 9.3 Case study}

\section{Gendered impact among healthcare workers}

Gendered vulnerabilities are strongly brought to the fore during crises: in the following case, not in the general public, but among healthcare workers themselves. Female healthcare workers in China spoke out about their menstruation struggles while battling the coronavirus epidemic. They barely had time to eat or drink, much less change their menstrual materials while working. With a shortage of personal protective equipment, doctors and nurses wore diapers to avoid using the toilet, to conserve their protective suits. Thousands of donations of menstrual hygiene products such as sanitary pads and period-proof underwear were made to these hospitals for the frontline workers, but 
these were rejected by the male hospital managers who didn't consider them "necessities" until a public outcry brought attention to the situation. Photos of female healthcare workers wearing ill-fitting hazmat suits that were designed for men drew further ire from the public for taking women's protective gear less seriously than men's.

Source: Li, 2020.

There is a clear need to integrate gender considerations and linkages to climate change into the health sector right from the beginning: starting with introducing the topic into the curriculum for medical, dental, nursing, allied health and paramedical students, and continuing the integration into daily routines such as grand rounds when they begin their careers in hospitals. This will ensure that the health system has an inflow of people who understand the links between climate change and health, especially among girls and women.

\section{Integration of health and gender concerns into climate change adaptation and mitigation policies}

National-level climate adaptation strategies must address the underlying causes of vulnerability and gender inequity, and bring a gender perspective to policy and programmes in order to develop sustainable and inclusive solutions.

The international response to climate change is governed by the United Nations Framework Convention on Climate Change (UNFCCC). The definition of "adverse impacts" in the framework includes "human health and welfare" along with "natural and managed ecosystems or on the operation of socio-economic systems' (UNFCCC, 1992). However, climate change impacts are largely assessed through environmental and economic perspectives, with limited considerations on health impacts. According to Article 4.f. of the UNFCCC, before the parties propose any new adaptation or mitigation initiatives, they shall assess its health benefits or negative impacts along with environmental and economic considerations. This article also recognises the importance of gender equity. Proper implementation of this provision of UNFCCC will address some of the concerns and open up more opportunities to attain equity (WHO, 2011).

Women play a key role in adaptation and mitigation strategies due to their role in natural resources management and in other productive and reproductive activities at the household and community levels. Women play a prominent role during natural disasters as they carry out the responsibilities of securing food for the family, fodder for livestock, etc., and take charge of children and the elderly. Women tend to actively share information related to community well-being when survival is at stake, and 
communities tend to fare better during natural disasters when women play a leadership role in early warning systems and reconstruction. The disaster response can be made easier and more effective by empowering them with knowledge and information. To achieve SDGs (especially SDG 2) in the context of climate change, women must be supported to become more resilient, and to empower themselves politically, socially and economically. This calls for a better understanding of pathways linking climate, women, agriculture and nutrition, to develop appropriate interventions.

\section{Key takeaways}

- Gendered differentials make women more vulnerable to health risks from climate change, including extreme weather events, temperature variations, air pollution, water contamination, water scarcity and food insecurity, with pregnant women being especially vulnerable.

- Health professionals need to become aware of these gendered differentials and promote a gender-sensitive approach in dealing with the impact of climate change on health.

- Policies and national action plans need to support and empower women to play a key role in adaptation and mitigation strategies.

\section{References}

Bartlett S. (2008), Climate change and urban children: impacts and implications for adaptation in low- and middle-income countries. Environment and Urbanization, 20(2), 501-519. doi: 10.1177/0956247808096125.

Birch, E. L., Meleis, A., \& Wachter, S. (2012). The urban water transition: Why we must address the new reality of urbanization, women, Water, and sanitation in sustainable development. wH2O: The Journal of Gender and Water, 1(1), 1. https://repository.upenn.edu/wh2ojournal/vol1/iss1/1

Cannon, T. (2002). Gender and climate hazards in Bangladesh. Gender and Development, 10, 45-50.

Chen, L. H., Knutsen, S. F., Shavlik, D., Beeson, W. L., Petersen, F., Ghamsary, M., \& Abbey, D. (2005). The association between fatal coronary heart disease and ambient particulate air pollution: Are females at greater risk? Environmental Health Perspectives, 113(12), 1723-1729.

Duncan, K. (2006). Global climate change, air pollution, and women's health. WIT Transactions on Ecology and the Environment, 99. doi: 10.2495/RAV060611

Kakkad, K., Barzaga, M. L., Wallenstein, S., Azhar, G. S., \& Sheffield, P. E. (2014). Neonates in Ahmedabad, India, during the 2010 heat wave: A climate change adaptation study. Journal of Environmental and Public Health, 2014, 946875. doi: 10.1155/2014/946875. Epub 2014 Mar 10. PMID: 24734050; PMCID: PMC3964840.

Khan, A. E., Scheelbeek, P. F. D., Shilpi, A. B., Chan, Q., Mojumder, S. K., Rahman, A., ... \& Vineis, P. (2014). Salinity in drinking water and the risk of (pre) eclampsia and gestational hypertension in coastal Bangladesh: A case-control study. PLoS One, 9(9), e108715. doi: 10.1371/journal.pone.0108715 
Kunzli, N., Jerrett, M., Mack, W. J., Beckerman, B., LaBree, L., Gilliland, F., ... \& Hodis, H. N. (2005). Ambient air pollution and atherosclerosis in Los Angeles. Environmental Health Perspectives, 113(2), 201-206.

Li, J. A. (2020, February 28). How China's coronavirus healthcare workers exposed the taboo on menstruation. South China Morning Post. https:// www.scmp.com/comment/opinion/article/3052524/how-chinas-coronavirushealth-care-workers-exposed-taboo

MacDonald, R. (2005). How women were affected by the Tsunami: A perspective from Oxfam. PLoS Medicine, 2(6), e178. doi: 10.1371/journal.pmed.0020178

Makhseed, M. A., Musini, V. M., Ahmed, M. A., \& Monem, R. A. (1999). Influence of seasonal variation on pregnancy-induced hypertension and/or preeclampsia. Australian and New Zealand Journal of Obstetrics and Gynaecology, 39(2), 196-199.

Oxfam Briefing Note. (2005, March). The tsunami's impact on women. https:// oxfamilibrary.openrepository.com/bitstream/handle/10546/115038/bntsunami-impact-on-women-250305-en.pdf? sequence=1\&isAllowed $=\mathrm{y}$

Shiva, V., \& Jalees, K. (2005). Water \& women: A report by Research Foundation for Science, Technology, and Ecology for National Commission for Women. Research Foundation for Science, Technology, and Ecology (New Delhi, India), \& National Commission for Women (India). Navdanya/RFSTE.

Shetty, D. (2019, 09 Feb). As Climate Changes Grows More Intense, Women in Battered Coastal Orissa Step Up. Bloomberg Quint. https:/www.bloombergquint. com/global-economics/as-climate-change-grows-more-intense-women-inbattered-coastal-odisha-step-up.

Sorensen, M., Daneshvar, B., Hansen, M., Dragsted, L. O., Hertel, O., Knudsen, L., \& Loft, S. (2003). Personal PM2. 5 exposure and markers of oxidative stress in blood. Environmental Health Perspectives, 111(2), 161.

WaterAid. (2002) Diseases related to water and sanitation. WaterAid.

WHO. (n.d.-a). Gender, climate change and health, public health \& environment department. https://www.who.int/globalchange/GenderClimateChangeHealth final.pdf

WHO. (n.d.-b) Gender fact sheet. https://www.who.int/health-topics/gender

World Health Organization. (2011) Gender, climate change and health. https://apps. who.int/iris/bitstream/handle/10665/144781/9789241508186_eng.pdf;jsessionid =B44841E6FD81F00FA5F5DF470EE96082 ?sequence $=1$ 